\title{
The spatiotemporal dynamic and spatial spillover effect of agricultural green technological progress in China
}

\author{
Yue Deng ${ }^{1} \cdot$ Yu Cui $^{1} \cdot$ Sufyan Ullah Khan ${ }^{2} \cdot$ Minjuan Zhao ${ }^{1} \cdot$ Qian Lu $^{1}$ \\ Received: 17 August 2021 / Accepted: 27 December 2021 / Published online: 4 January 2022 \\ (c) The Author(s), under exclusive licence to Springer-Verlag GmbH Germany, part of Springer Nature 2022
}

\begin{abstract}
The progress of agricultural green technology is an important means and fundamental way to achieve high-quality development of agriculture. The current study takes the panel data of 31 provinces in China from 1998 to 2018 and uses the Epsilon Based Measure-Global Malmquist-Luenberger (EBM-GML) model to measure China's agricultural green technological progress (AGTP) and discusses its dynamic evolution characteristics in the spatiotemporal dimensions. Finally, we analyze the spatial spillover effects of AGTP by the spatial Dubin model. The results show that China's AGTP showed a trend of first rising and then falling, and the average value is 1.0525. AGTP has obvious regional unbalanced development, and the regional differences are expanding. It shows that AGTP between adjacent areas is closely linked. The Moran's I index shows that AGTP has a significant positive spatial correlation. The local Moran's I index shows that AGTP is concentrated in Northwest, Northeast, and North China, and green technological is degraded in East and South China. From the spatial spillover effects of AGTP, the level of agricultural economic development, real GDP per capita, and urbanization have significantly promoted AGTP in the local and neighboring areas, while the agricultural internal structure and the level of labor inhibit AGTP in the local and neighboring areas. In addition, the administrative environmental policy (ENVP) and the economic environmental policy (ECOP) have negative impacts in neighboring areas, while the policy has negative spillover effects and positive spillover effects in the local area, respectively. Therefore, we should adhere to the concept of green development, pay attention to the regional exchange of green technology, concentrate policies on low-low concentration areas, and increase the follow-up tracking and supervision mechanism of the policy design and implementation process.
\end{abstract}

Keywords Agricultural green technological progress - Temporal and spatial dynamic evolution - Spatial spillover effect . EBM-GML · Agriculture industry

Responsible Editor: Philippe Garrigues

Minjuan Zhao

minjuan.zhao@nwafu.edu.cn

Yue Deng

dengyuenote@163.com

Yu Cui

cui2018060454@163.com

Sufyan Ullah Khan

drsufyan@xaiu.edu.cn

Qian Lu

luqian@nwafu.edu.cn

1 College Economic \& Management, Northwest Agriculture and Forestry University, 3 Taicheng Rd, Yangling 712100, Shaanxi, China

2 College of International Cooperation, Xian International University, 18 Yu Dou Lu, Yanta District, Xian 710077, Shaanxi, China

\section{Introduction}

Against the backdrop of economic globalization and an everincreasing global population, the agricultural economy's fast expansion is heavily reliant on organic inputs such as pesticides and fertilizers. This causes soil acidity and compaction, a loss in soil fertility, heavy metal contamination, and other issues. The growing trend of high-energy consumption, high emissions, and high pollution has significantly hampered agriculture's sustainable development and jeopardized food security. According to statistics, the total annual chemical fertilizer application in China's agriculture exceeds $1 / 3$ of the global total, and the average application intensity exceeds $440 \mathrm{~kg} / \mathrm{ha}$, which is 2.8 times the average global fertilizer application intensity. The annual pesticide application rate has exceeded 300,000 tons, and the application intensity has reached $25 \mathrm{~kg} / \mathrm{ha}$, which is three 
times the world average (Guo et al. 2020). Agricultural water accounts for more than $60 \%$ of total water use in the national economy, and agricultural irrigation water efficiency is only $75 \%$ of that of developed countries (Wang et al. 2018a). The excessively intense factor production technique has not only resulted in significant pollution of water and agrochemicals but has also resulted in a double-constraint dilemma on water and soil resources. The progress of agricultural green technology is an important means and fundamental way to achieve high-quality development of agriculture. Building a market-oriented green technology innovation system and promoting green development has become an important means to solve these problems.

After Acemoglu et al. (2000, 2007, 2011, 2012) proposed the endogenous theory of technological development and the theory of technological progress deviations. It has become the focus of many academic circles to investigate whether technological progress is biased toward saving resources and energy input and reducing pollution emissions. Based on this, the academic community extended the idea to the environment (Acemoglu et al. 2012) and put forward the concept of green technological progress. In addition, according to incomplete statistics, terms related to green technological progress include: environment biased technical progress (Yang et al. 2020a), environmental technology innovation, green technology innovation (Razmi 2013), cleaner technology progress (Fischer and Heutel 2013), and their essence is not much different. They are progress activities that are only oriented to improve environmental performance or can bring significant environmental performance improvement results. Academic circles mostly adopt the substitution method of scientific publication data or patent indicators (Doranova et al. 2010; Popp 2004). Total factor productivity (TFP) (Fischer and Heutel 2013), DEA-Malmquist, and SBMMalmquist methods (Kou et al. 2016) measure the progress of green technology.

In the field of agriculture, academic circles mainly involve green technological progress or environmental technological progress based on agricultural green technology efficiency or environmental technology efficiency research. There are few papers on the progress of agricultural green technology. From the related research of China's AGTP, it can be found that ignoring environmental factors will overestimate the growth of China's agricultural productivity. Under environmental constraints, agricultural technological progress in various areas of China is increasing while showing the descending characteristics of eastern areas, western areas, and central areas, the northeast area showed a technological decline, and the progress of non-environmental technology decreased from east to west areas (Li 2014; Shuqin et al. 2019) studied China's agricultural green productivity under the dual constraints of resources and the environment, and found that the cutting-edge technological progress in
1978-1984, 1985-1991, 1992-1996, 1997-2001, and 2002-2008 contributed $10.23 \%, 2.9 \%, 5.03 \%, 8.29 \%$, and $5.01 \%$, respectively. At the same time, some studies have pointed out that green technological progress has an evident path dependence characteristic, and the rate of green technology progress at the early stage can affect the rate at the later stage (Yang et al. 2020b). In addition, Ren and Zeng (2021) evaluated the suitability of green technological progress in the mariculture industry and concluded that nearly half of the provinces have chosen a direction of green technological progress that is not consistent with their factor endowments.

In addition to the measurement of green technological progress and the analysis of temporal and spatial differences, the socio-economic factors leading to the differences in green technological progress are also a new research direction. Relevant scholars have studied environmental regulations (Xu 2021; Zhang et al. 2018), trade (Lovely and Popp 2011), market pull (Horbach et al. 2012), wave destruction (Yang et al. 2020b), industrial structure (Yang et al. 2020a), average green patents in transportation, industrial scale, and local government financial expenditure (Zhang et al. 2020) on green technological progress or green technology innovation. Although the research fields are different, these studies also provide important analytical ideas for the in-depth discussion of agricultural green technological progress. In the agriculture industry, Li. and Z. (2020) found that the level of income, the level of agricultural human capital, the proportion of grain sown area, the income gap between urban and rural areas, and the support of agricultural policy can help to increase AGTP, whereas increasing the level of urbanization and fertilizer application will hinder its development. According to $\mathrm{Ji}$ and $\mathrm{Li} \mathrm{(2019),} \mathrm{the} \mathrm{major} \mathrm{variables} \mathrm{influenc-}$ ing the growth of green technology in the marine aquaculture sector are technological promotion and development scale, while the influence of science and education input elements is insignificant. He et al. (2021) found Agricultural technologies' diffusion, absorption, implementation, the level of informatization, the number of agricultural technicians in enterprises and institutions, average education level of residents, and the level of agricultural mechanization, absorption, and implementation of agricultural innovation technology can significantly influence the green efficiency of agricultural innovation.

In conclusion, past studies have expanded research ideas for the advancement of agricultural green technology and established a theoretical framework for future study, but there were some research gaps or limitations. Firstly, the advancement of green technology serves as an important support for the green development of the agriculture industry. In-depth comments on the advancement of green technologies for the agriculture sector are lacking in existing research. There are few analyses on the progress of 
agricultural green technology. What is the changing trend of these green technologies? Has the progress of green technology enhanced over time? The regional differences and dynamic characteristics of AGTP need to study. Secondly, the factors affecting the progress of agricultural green technology may also show temporal and spatial heterogeneity. In particular, China has a vast territory, and there are obvious regional differences in the endowment of agricultural production factors. Influencing factors may also show spatiotemporal heterogeneity. With the development of the economy and the transfer and diffusion of technology, the spatial spillover effect of green technological progress in China's agriculture industry needs to document.

When compared to previous studies, this study has improved in two major areas. First, the EBM-GML model is used to assess the advancement of agricultural green technology, and the efficiency value's divergence is rectified. Second, in this work, the spatial correlation of green technological advancement via ESDA is employed, and the spatial spillover impact of agriculture green technological progress (AGTP) under diverse regional backgrounds have also been proven. Finally, this article takes the agriculture industry as the research object, and the status quo and challenges of AGTP in the agriculture industry are confirmed. To some extent, the findings of this study may be utilized to develop relevant green technology utilization strategies and management systems in various areas of China.

The specific objectives of this study are as follows: to explore and verify the changing trend of green technology in China since 1998-2018 and whether the elapsed time has been improved, exploring and studying the spatial difference of AGTP, expecting to master the spatial change dynamics of the level of AGTP among regions in China after the transfer, and the diffusion of green technology. Grasp the spatial and temporal pattern and influencing factors of green technology progress so that policy designers in different regions can adopt green technology progress strategies according to local conditions, which is of great significance to provide lessons for further promoting China's agricultural green development policy.

The theoretical contributions of this study are as follows: compared with the traditional agricultural environmental protection and governance, agricultural green development is a benign development strategy and development model that integrates environmental sustainability into economic and social sustainable development. Targeted research on green technological progress can enrich the theory of China's green agriculture, green technological progress, and ecological environment. In addition, the study of spatial-temporal heterogeneity of green technological progress from the perspective of geospatial interaction also enriches the value of spatial heterogeneity theory. The practical contributions of this study are as follows: the space-time dimension is an important way to describe the information and development rules of things. The analysis of the time-space dynamic evolution of green technological progress in this study can better reflect the reality of agricultural green technological progress. At the same time, analyzing the spatial spillover effects of various factors on the progress of agricultural green technology is also more conducive to the formulation and implementation of regional technology progress policies.

The rest of this study is organized as follows. The material and method section introduces methods and data, including (EBM-GML) and the spatial Dubin model. The results and discussion section introduces the temporal and spatial characteristics of agriculture green technological progress (AGTP) and the estimated results of dynamic evolution. We also provided the test results of direct and indirect effects under the spatial Dubin model. The conclusion and suggestions section is the conclusion and policy implications.

\section{Material and methods}

\section{Measurement method and index selection}

\section{Epsilon-based measure-global Malquist-Luenberger (EBM-GML)}

Since technological progress is an intangible variable, it is difficult to measure directly. Therefore, the measurement research on the progress of green technology has always been a key problem in this field. The first is the index substitution method. Use scientific publication data, patent data, etc. to measure the progress of green technology (Doranova et al. 2010; Popp 2004), but Liu et al. (2020) believe that the number of patents reflects the direct impact of green technology innovation. Evaluation of green technology innovation capabilities will produce bias. Secondly, using TFP to comprehensively reflect the green technological progress index (Feng and Serletis 2014). However, their findings on "total factor productivity with consideration of energy input and pollution emission factors" do not reflect the true connotation of biased technological progress ( $\mathrm{Ji}$ and Wang 2014; Song et al. 2016). Finally, a nonparametric estimation method was commonly used to measure the progress of green technology and included DEA-ML and SBM-ML methods to measure it (Kou et al. 2016). But DEA model assumes that the return on the scale is unchanged, which is contrary to the real economic phenomenon, and the SBM model loses the original proportional information of the front projection value of efficiency, and when the optimal relaxation takes 0 and positive value, the results will be significantly different. To solve these problems effectively, this study refers to Tone (2001) and constructs a mixed distance 
function EBM model with radial and non-radial characteristics, and its expression is as follows:

$\min \gamma^{*}=\theta-\varepsilon x \sum_{i=1}^{m} \frac{w s_{i}^{-}}{x_{i o}}$

st. $X \lambda-\theta x_{i o}+s=0, Y \lambda \geq 0, s_{i}^{-} \geq 0$

where $E$ represents input, $L$ represents output, and $\mathrm{Si}^{-}$represents input relaxation vector; $\gamma^{*}$ is the value of agricultural green total factor productivity in each province; $\theta$ is the radial component in $\gamma^{*} \varepsilon_{\mathrm{x}}$ is a key parameter with a value of $[0,1]$, which represents the importance of the non-radial part in the calculation of the efficiency value. When it is set to 0 , it is equivalent to the radial model, and when it is set to 1 , it is equivalent to the SBM model.

In order to further decompose the progress of green technology, we draw on the research ideas of (Oh 2010), and on the basis of calculating the green TFP, the GML index decomposition method (global Malmquist-Luenberger) is introduced to obtain the AGTP index. The GML index method is obtained by constructing a global production possible set, and its formula is as follows: is the bandwidth. The bigger w, the smoother the density function curve of AGTP, the estimation accuracy will decrease accordingly. Therefore, a smaller $w$ is generally selected in actual research.

$K(x)=\frac{1}{\sqrt{2 \pi}} \exp \left(-\frac{x^{2}}{2}\right)$

According to the different expression forms of the Kernel density function, the kernel function can be divided into uniform kernel density method, quadratic kernel density method, and Gaussian kernel density method (Gerber 2014). We choose the Gaussian kernel density function to estimate the distribution dynamics of China's AGTP. The function expression of the Gaussian kernel is shown in Eq. (4). Since there is no definite functional expression for nonparametric estimation, it is necessary to compare the position, shape, and ductility of the graph distribution to investigate the change of the distribution.

\section{The method of spatial autocorrelation (ESDA)}

Moran's $I$ and Anselin Local Moran's $I$ are an analysis

$G M L^{t, t+1}\left(x^{t}, y^{t}, b^{t}, x^{t+1}, y^{t+1}, b^{t+1}=\frac{E^{G, t+1}\left(x^{t+1}, y^{t+1}, b^{t+1}\right)}{E^{G, t}\left(x^{t}, y^{t}, b^{t}\right)}=\frac{E^{G, t}\left(x^{t+1}, y^{t+1}, b^{t+1}\right)}{E^{G, t}\left(x^{t}, y^{t}, b^{t}\right)} \times \frac{E^{G, t+1}\left(x^{t+1}, y^{t+1}, b^{t+1}\right) / E^{t+1}\left(x^{t+1}, y^{t+1}, b^{t+1}\right)}{E^{G, t}\left(x^{t}, y^{t}, b^{t}\right) / E^{t}\left(x^{t}, y^{t}, b^{t}\right)}=G M L E C^{t, t+1} \times G M L T C^{t, t+1}\right.$

$E^{G, t+1}$ represents the overall efficiency value in $t+1$ period. The GML index is the green total factor productivity index, which can be decomposed into green technology efficiency (GMLEC) and green technological progress (GMLTC). When the value is greater than 1, it represents green technological progress; when the value is less than 1, it means that the green technology has regressed; the value equal to 1 means that the level of green technology remains unchanged. The green technological progresses in this study are all completed with MaxDEA 7.12 version.

\section{Kernel density estimation method}

Because the nonparametric estimation of the Kernel density estimation method has a weak dependence on the model and is robust, it has become a common method for studying unbalanced distribution (Qin and Xiao 2018b, a). This article uses this method to analyze the dynamic distribution characteristics of China's AGTP. The specific formula is

$F(\bar{x})=\frac{1}{N w} \sum_{i=1}^{N} K\left(\frac{X_{i}-\bar{x}}{w}\right)$

In Eq. (3), $F(\bar{X})$ represents the density function of AGTP, $\bar{X}$ is the mean, $N$ indicates the number of observations, $X_{i}$ is independent and identically distributed observations, and $w$ method widely used to study spatial correlation (Pan et al. 2015). The current study uses two methods to verify the spatial correlation of China's AGTP. The specific equation is as follows:

$I=\frac{n \sum i \sum j W_{i j}\left(X_{i}-\bar{X}\right)\left(X_{j}-\bar{X}\right)}{\sum i \sum j W_{i j}\left(X_{j}-\bar{X}\right)}$

$I_{i}=\frac{n\left(X_{j}-\bar{X}\right)}{S_{X}^{2}} W_{i j}\left(X_{j}-\bar{X}\right)$

Equation (5) is Moran's $I, n$ is the total number of cities, $W_{i j}$ is the spatial weight, $X_{i}$ and $X_{j}$ are the attributes of the city $i$ and $j$, respectively, and $\bar{X}$ is the mean value of the attribute. Equation (6) is Moran's $I . S_{X}^{2}$ is the variance of the observations, the formula is $S_{X}^{2}=\sum_{j} W_{i j}(X j-\bar{X}) / n$.

\section{Spatial Dubin model}

At present, the mainstream research methods of spatial metrology include the spatial lag model (SLM), spatial error model (SEM), and spatial Dubin model (SDM). Compared with the SLM and SEM models, the SDM model considers the spatial correlation of the dependent variable and the 
spatial correlation of the independent variables. At the same time, it also has spatial autocorrelation and spatial interaction effects. In addition, for endogenous problems, the SDM model can be used to get the estimated value that is not amplified and biased (Elhorst and Paul 2014, Lesage and Pace 2008; Wang et al. 2018b). Therefore, we use this model to examine the impact of each variable on the progress of agricultural green technology and the spatial spillover effect. The model is set as follows:

$Y=\partial+\beta W y+\beta X+W X \gamma+\varepsilon$

$Y$ is the dependent variable, $\beta$ is the spillover effect of neighboring provinces, $X$ is the independent variable, $\beta$ and $\gamma$ are the parameters to be estimated, and $W$ is weight. In order to increase the robustness of the model, we refer to the study of Wang et al. (2018b) to construct three spatial weight matrices, including spatial adjacency weight matrix, geographic distance weight matrix, and geographic economic distance spatial weight.

\section{Data sources}

This study takes the narrow agriculture industry as the research object, including the data of 31 provinces (cities and autonomous regions) of China (excluding Hong Kong, Macao, and Taiwan) from 1998 to 2018. The data used includes input data including employees of agriculture industry, chemical fertilizers, pesticides, agricultural film, agricultural diesel, total power of the agricultural machinery and agriculture area, the output includes the expected output of the agriculture industry total output value, and undesired output carbon emissions. The data used are from the "China Rural Statistical Yearbook," "China Agricultural Statistical Yearbook," and "China Fishery Statistical Yearbook." In addition, the total power data of agriculture machinery is obtained by subtracting the total power of forestry, animal husbandry, and fishing machinery from the total power of farming, forestry, animal husbandry, and fishery machinery in the current year. The data of agriculture industry employees is calculated by multiplying the number of people employed in agriculture, forestry, animal husbandry, and fishery that year by the ratio of the total output value of the agriculture industry and the total output value of agriculture, forestry, animal husbandry, and fishery that year.

\section{Index selection}

Green agriculture is an agricultural development model based on technological progress, integrating energy conservation, protecting and improving the agricultural ecological environment, and advocating a green consumption lifestyle (Wanzenboeck et al. 2016). According to the literature summary and research results, if the market subject and regional environment are taken as the mainline, the internal promotion mechanism of AGTP can be attributed to the level of agricultural development, interregional interaction, and regional policy environment (Vocke and Heady 1978; Zhang et al. 2021). The internal mechanism of these three aspects will effectively promote green sustainable production and promote the progress of agricultural green technology. On this basis, learn from the research of scholars $(\mathrm{Li}$ 2014, Li, 2020, Li. and Z. 2020, Vocke and Heady 1978, Zhang et al. 2021), and based on the availability of data. We choose the research of relevant scholars (in Table 1, the detailed description of index selection is provided in the supplementary file) and select indicators to explore the spatial spillover effect of green technological progress and its role in green technological progress. The descriptive statistical analysis results of specific indicators are shown in Table 1 .

\section{Results and discussion}

\section{The spatiotemporal characteristics and dynamic evolution of AGTP}

\section{The spatiotemporal characteristics of AGTP}

According to the EBM-GML model, we calculated the AGTP index of each province in China's agriculture industry from 1998 to 2018. Table 2 only shows the AGTP index of $1998,2005,2012$, and 2018. Other data can be found in the supplementary file. From the perspective of time, there were 14 provinces in 1998 and 2005 that saw green technological progress. In 2012 and 2018, the decline of green technology decreased significantly, but the extent of the decrease was not obvious, it is even lower in 2018 than in 2012. From a spatial perspective, the 5 provinces, including Shandong, Jilin, Zhejiang, Beijing, and Hainan always in a state of AGTP, this has played a role in demonstrating and driving AGTP. According to the average value of the AGTP index in Table 1, all regions demonstrated a state of green technology advancement from 1998 to 2018. This demonstrates that the general growth of green technology in China's agriculture industry is increasing; however, there are some variations across provinces. As a result, additional research into the dynamic changes of AGTP in China's agriculture sector is required.

We develop a line chart of time-series changes to compare and assess the time-series features of AGTP in the three key areas of Central, East, and West (Fig. 1). It can be observed that the progress of agricultural green technology in the three key areas is dynamic and increasing, and the changing pattern is essentially the same. It can be divided into three stages, the first stage is the continual optimization and 
Table 1 Descriptive statistics of related variables

\begin{tabular}{|c|c|c|c|c|c|c|}
\hline Variable & Index description & Minimum & Maximum & Average & SD & References \\
\hline $\begin{array}{l}\text { Green technological progress } \\
\text { (AGTP) }\end{array}$ & The index of EBM-GML (\%) & 0.51 & 2.41 & 1.05 & 0.13 & (Oh 2010) \\
\hline $\begin{array}{l}\text { Agricultural economic develop- } \\
\text { ment level (eco) }\end{array}$ & $\begin{array}{l}\text { The gross production value of } \\
\text { agriculture industry (100 mil- } \\
\text { lion yuan) }\end{array}$ & 22.40 & 4973.70 & 1071.50 & 1035.19 & (Levain et al. 2015) \\
\hline GDP per capita (rjgdp) & $\begin{array}{l}\text { The total output value of } \\
\text { agriculture industry/total } \\
\text { agricultural population }\end{array}$ & 0.00 & 11.00 & 2.64 & 2.01 & (Nyam et al. 2021) \\
\hline The level of labor (labor) & $\begin{array}{l}\text { The employed population of } \\
\text { agriculture industry (million } \\
\text { people) }\end{array}$ & 16.97 & 2277.09 & 508.29 & 404.78 & (Emilio et al. 2018) \\
\hline The level of urbanization (city) & $\begin{array}{l}\text { The urbanized population/total } \\
\text { population }(\%)\end{array}$ & 0.04 & 0.90 & 0.45 & 0.18 & $\begin{array}{l}\text { (Morya and Punia, Onanuga } \\
\text { et al. 2021) }\end{array}$ \\
\hline $\begin{array}{l}\text { Internal structure of agriculture } \\
\text { (agst) }\end{array}$ & $\begin{array}{l}\text { The gross production value } \\
\text { of agriculture industry/the } \\
\text { production value of agricul- } \\
\text { tural }(\%)\end{array}$ & 0.30 & 1.85 & 0.53 & 0.10 & (Li J 2020) \\
\hline $\begin{array}{l}\text { The environmental policy of } \\
\text { administrative (ENVP) }\end{array}$ & $\begin{array}{l}\text { The number of environmental } \\
\text { regulation policies imple- } \\
\text { mented at the provincial level } \\
\text { in the year (pieces) }\end{array}$ & 0.00 & 388.00 & 25.56 & 39.87 & (Xu 2021; Zhang et al. 2018) \\
\hline $\begin{array}{l}\text { The environmental policy of } \\
\text { economic (ECOP) }\end{array}$ & $\begin{array}{l}\text { Pollution control project com- } \\
\text { pleted investment this year/ } \\
\text { GDP }(\%)\end{array}$ & 0.33 & 99.19 & 16.33 & 13.88 & (Xu 2021; Zhang et al. 2018) \\
\hline
\end{tabular}

Table 2 The index of agriculture green technological progress (AGTP) in China's agriculture industry

\begin{tabular}{lccccclclllll}
\hline Province & 1998 & 2005 & 2012 & 2018 & Mean & Province & 1998 & 2005 & 2012 & 2018 & Mean \\
\hline Eastern areas & & & & & & Henan & 0.972 & 0.847 & 1.080 & 1.000 & 1.065 \\
Beijing & 1.057 & 1.091 & 1.102 & 1.000 & 1.052 & Hubei & 1.020 & 0.987 & 1.051 & 1.000 & 1.065 \\
Tianjin & 0.528 & 1.088 & 1.135 & 1.293 & 1.018 & Hunan & 0.924 & 0.960 & 1.023 & 1.062 & 1.064 \\
Hebei & 0.949 & 0.771 & 1.159 & 1.056 & 1.061 & Guangxi & 1.069 & 0.892 & 1.056 & 0.980 & 1.053 \\
Shanghai & 0.766 & 1.184 & 0.997 & 1.138 & 1.045 & Jilin & 1.247 & 1.103 & 1.048 & 1.076 & 1.068 \\
Jiangshu & 0.985 & 0.887 & 1.054 & 1.000 & 1.055 & Heilongjiang & 0.901 & 0.981 & 1.195 & 1.000 & 1.050 \\
Zhejiang & 1.046 & 1.017 & 1.082 & 1.000 & 1.057 & Western areas & & & & \\
Fujiang & 0.987 & 1.035 & 1.073 & 1.000 & 1.057 & Chongqing & 0.947 & 0.946 & 1.067 & 1.089 & 1.049 \\
Shandong & 1.095 & 1.149 & 1.167 & 1.111 & 1.112 & Sichuan & 0.978 & 0.964 & 1.029 & 1.000 & 1.055 \\
Hainan & 1.000 & 1.001 & 1.135 & 1.000 & 1.010 & Guizhou & 1.029 & 0.902 & 1.083 & 1.000 & 1.041 \\
Guangdong & 0.941 & 1.007 & 1.081 & 1.000 & 1.041 & Yunnan & 1.080 & 1.056 & 1.060 & 1.119 & 1.058 \\
Liaoning & 1.147 & 0.943 & 1.062 & 1.075 & 1.068 & Tibet & 1.000 & 1.086 & 0.952 & 1.000 & 1.002 \\
Central areas & & & & & & Shaanxi & 1.036 & 0.941 & 1.081 & 1.000 & 1.053 \\
Shanxi & 0.884 & 1.014 & 1.076 & 1.050 & 1.055 & Gansu & 1.057 & 1.041 & 1.055 & 1.143 & 1.053 \\
In. Mongolia & 1.104 & 1.056 & 1.078 & 1.091 & 1.064 & Qinghai & 1.045 & 1.215 & 1.056 & 1.000 & 1.030 \\
Anhui & 0.956 & 1.011 & 1.057 & 0.990 & 1.063 & Ningxia & 1.244 & 1.462 & 1.090 & 1.000 & 1.045 \\
Jiangxi & 0.879 & 0.871 & 1.025 & 1.064 & 1.062 & Xinjiang & 1.327 & 1.269 & 1.028 & 1.000 & 1.057 \\
\hline
\end{tabular}

enhancement of AGTP from 1998 to 2008, which seems to be a period of rapid economic development and urban-rural convergence. Rural surplus workforce entering the city, a rise in high agricultural scientific research, and more market potential have enhanced agricultural production efficiency and fueled the agricultural economy's rapid expansion.
AGTP The overall performance is the improvement of AGTP. Second, agricultural green technology progress remained mostly constant between 2011 and 2014. Because large-scale production aided the growth of the agricultural economy in the early stages, the efficiency of green investment and factor allocation briefly approached the optimal 
Fig. 1 Time series characteristics of AGTP in China's agriculture industry

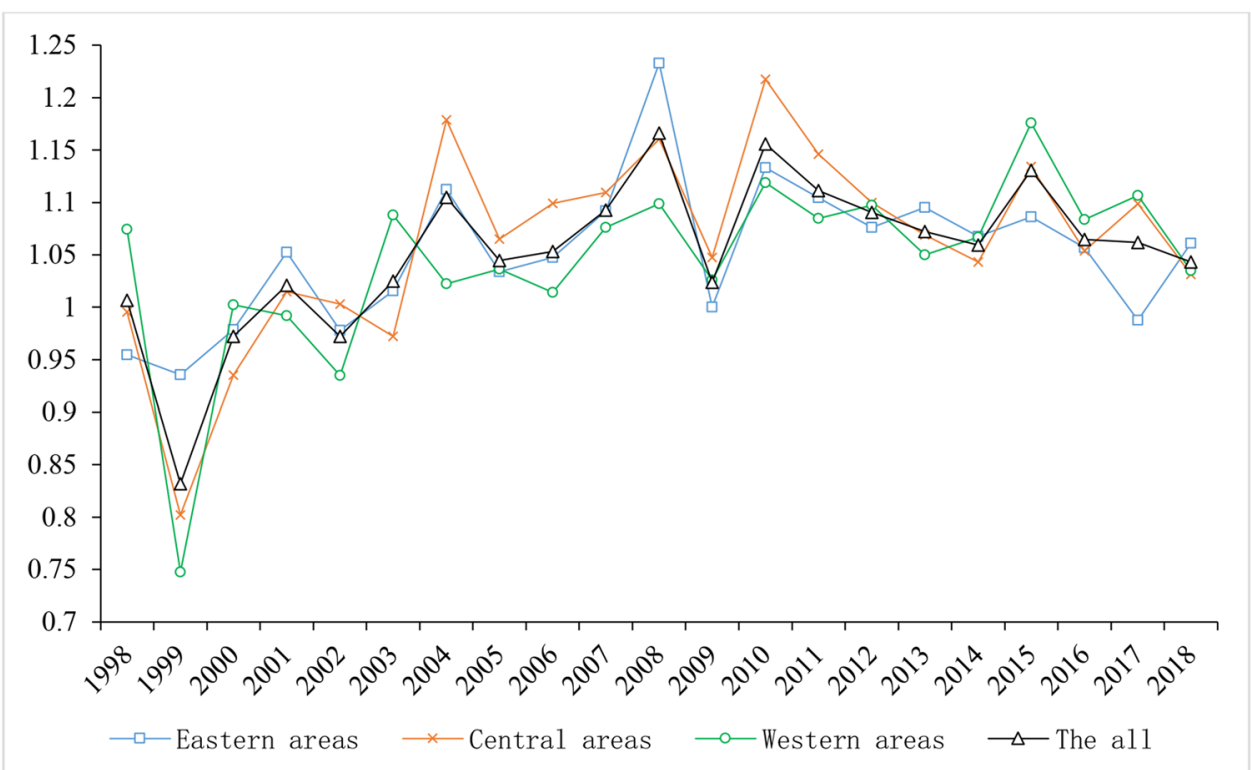

allocation state. As a result, the external market potential was largely saturated during this time period. Third, agricultural green technology progress slowed somewhat between 2015 and 2018. During this time, the issue of capital accumulation in the external market became apparent, resulting in a reduction in green investment efficiency and a diversion of factor allocation, which hampered the progress of green technology. Nevertheless, because the government promotes the green development idea of "adjusting structure, transforming techniques, and encouraging modernization," the problem of agricultural green technology deterioration is not severe.

Differences in resource endowments and economic development levels have caused certain differences in the level of AGTP in various provinces. In order to reflect the spatial spillover laws and spatial gradient effects of AGTP in China's agriculture industry, we use ArcGIS software to draw a spatial distribution map of China's AGTP in 1998, 2005, 2012, and 2018, as shown in Fig. 2. In 1998, it can be seen that the progress of green technology was not obvious, accounting for only 55\%. Northwest, Northeast, and North China are the main gathering areas of AGTP. East China and South China are the main areas where green technology has degraded. The possible reason is that in the 1990s, high agricultural yields and maximizing economic benefits were the main goals pursued in East China and South China. It ignores the protection of the ecological environment to a certain extent, blindly invests in work and fertilizer, and has seen the phenomenon of green technology regressing. In 2005 , there were 24 progresses in agricultural green technology, accounting for $78.5 \%$. The decline of green technology was mainly concentrated in the southwest. During this period, the development of the market economy and the professionalization of the agriculture industry's science and technology teams accelerated the promotion of green production technology, and other achievements enhanced the awareness of ecological environment protection. In 2012, the proportion of AGTP in 31 provinces reached $96.78 \%$, and the AGTP index reached 1.1768, which was the best year for AGTP. The main reason is that the government gradually implements the coordinated development of alternative technologies and improved technologies. In 2018, 64.52\% of provinces have maintained the same level of green technology in China's agriculture industry. The main reason is that the efficiency of green investment and the allocation of factors in the early stage have reached the optimal allocation state. In addition, the progress of green technology in the northwestern area was significantly higher than that in the eastern area in 1998, 2005, and 2012. The possible reason is that due to the constraints of natural and economic conditions, the northwestern area is an area with a fragile ecological environment and underdeveloped economy, and its agriculture industry has always paid attention to green ecological environmental protection.

\section{The dynamic evolution of AGTP in China's agriculture industry}

In order to intuitively understand the dynamic evolution characteristics of AGTP in China's agriculture industry, we take 1998, 2005, 2012, and 2018 as the survey years, and use the Kernel density estimation method to analyze the time dynamic evolution trend of AGTP, as shown in Fig. 3. It can be seen that the dynamic evolution of AGTP in China's 31 provinces from 1998 to 2018 has the following characteristics: (1) from the perspective of location distribution, the 
Fig. 2 The spatial distribution characteristics of AGTP in China's agriculture industry
Fig. 3 The kernel density estimation of AGTP in China's agriculture industry
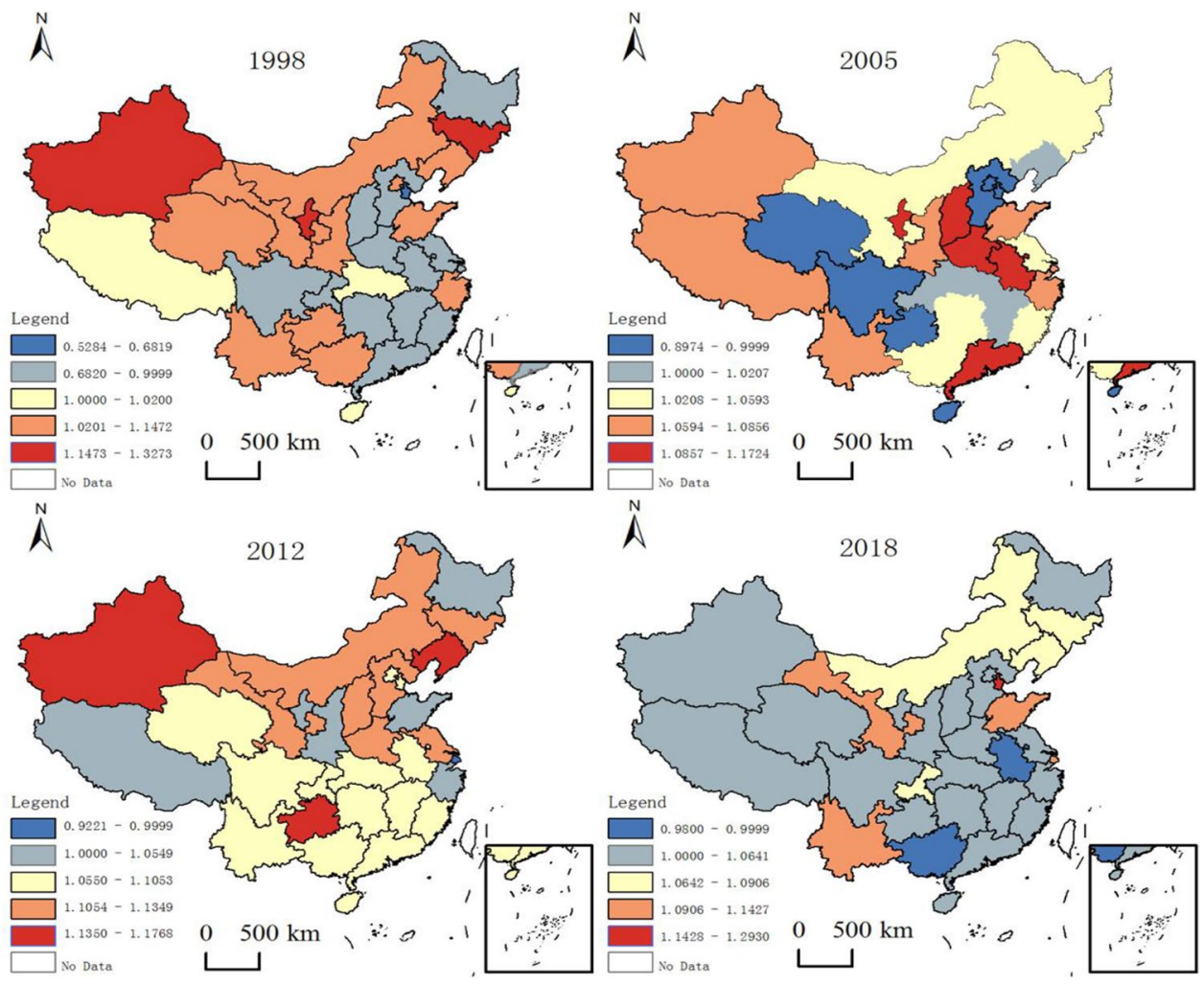

^
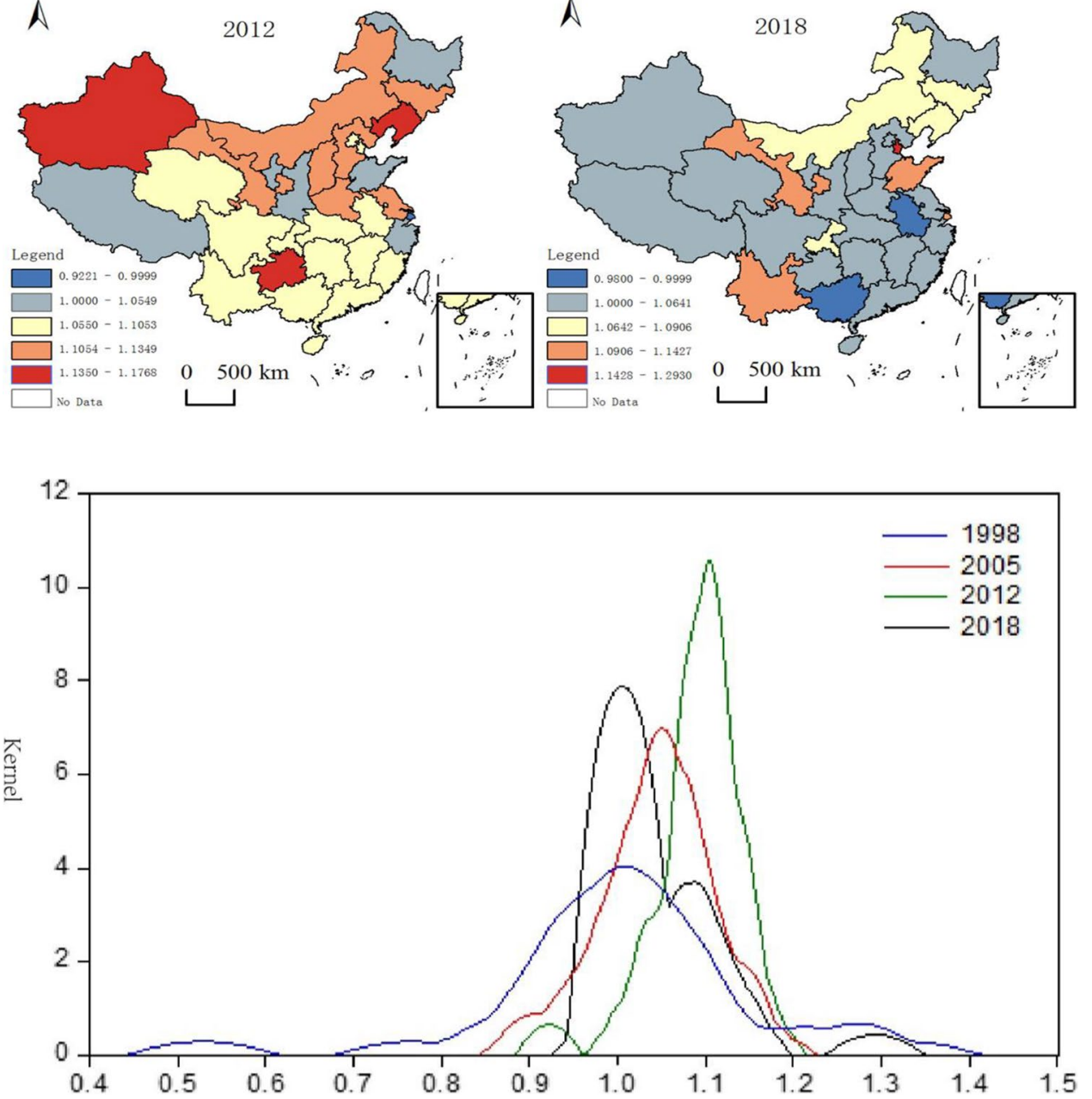

center of the national overall distribution curve has experienced a "right shift-left shift" trend. Among them, the density distribution curve from 1998 to 2012 shifts to the right. It shows that the agriculture industry's AGTP is showing an upward trend. The distribution curve from 2012 to 2018 shifts slightly to the left. This shows that the progress of green technology has declined at this stage, showing a trend of technological decline. (2) From the perspective of the distribution pattern, the wave crest changed from a single peak in 1998 to a double peak in 2018. The width of the main peak is characterized by the transition of "broad peaksharp peak-broad peak." Among them, the period from 1998 to 2012 was dominated by a single peak, and the kurtosis decreased year by year. The peak shape changes from "broad peak" to "sharp peak," and the horizontal span of the density distribution curve is reduced. It shows that each province is at a high level of AGTP and the degree of concentration has increased, and regional differences have narrowed. From 
a single peak to a double peak in 2012-2018, the kurtosis decreased year by year. The peak shape changes from a weak "spike" to a "broad peak," and the horizontal span of the density distribution curve becomes wider. This means that with the development of the economy and the gradual improvement of the level of agricultural modernization, the differences between areas are gradually widening. The gradual "outdated" level of AGTP in some provinces has led to a decline in the overall level of technology concentration and widening regional differences. The above analysis also shows that there is an uneven regional development in the Chinese agriculture industry's AGTP.

\section{Empirical results and analysis}

The "spillover effect" alludes to the notion that when a particular group or organization engages in a specific activity, in addition to the expected effects it might create, it could have an unexpected impact on groups other than the organization. In the context of this research, the spillover effect indicates that within a certain location, the development of green technology in the agriculture industry in the local region may promote or inhibit the growth of green technology in the immediate neighborhood. From the temporal and spatial dynamic evolution characteristics of AGTP, we can see that AGTP has obvious temporal and spatial heterogeneity in China's agriculture industry. As a result, an in-depth assessment of the mechanisms causing this difference and whether it has spatial spillover advantages is required.

\section{Spatial autocorrelation test}

In order to analyze the relevance of AGTP between regions, we use the global Moran's I and the Local Moran's I to test their spatial relevance. The results are shown in Table 3 and Fig. 4.

As shown in Table 3, the global Moran's I statistics are significant under the $10 \%$ level of significance, and both are greater than zero. This shows that there is a positive spatial correlation in the progress of agricultural green technology in various provinces in China. From the local autocorrelation LISA cluster map of the AGTP index in 1998 and 2018 (Fig. 4), it can be seen that the AGTP of China's 31 provinces shows an obvious spatial imbalance. The overall cluster is "high-high" and "low-high." This shows that there is a strong positive spatial correlation between the progress of green technology in China's provinces. That is, most provinces are adjacent to the location, or the economic development level is close to the provinces showing similar agglomeration characteristics. The provinces belonging to the "high-high" agglomeration area are located in the southwest (1998) and northeast (2018) and have special advantages in agricultural resource endowments. In particular, the
Table 3 The Moran's I statistics of Chinese agriculture industry's AGTP in 1998-2018

\begin{tabular}{llllll}
\hline Year & Moran's $I$ & $Z$-value & Year & Moran's $I$ & $Z$-value \\
\hline 1998 & -0.02066 & 0.171612 & 2009 & -0.07644 & -0.73133 \\
1999 & 0.095506 & 1.654413 & 2010 & 0.021197 & 0.719458 \\
2000 & 0.00417 & 0.490302 & 2011 & -0.05971 & -0.34177 \\
2001 & 0.324151 & $4.771178^{*}$ & 2012 & -0.0304 & 0.039725 \\
2002 & 0.087163 & $1.709623^{*}$ & 2013 & 0.186519 & $2.887275^{*}$ \\
2003 & -0.02919 & 0.055367 & 2014 & 0.001333 & 0.500758 \\
2004 & 0.03857 & 0.939415 & 2015 & 0.050896 & 1.297294 \\
2005 & 0.072932 & 1.378816 & 2016 & 0.227033 & $3.323797 *$ \\
2006 & 0.046953 & 1.039502 & 2017 & 0.228646 & $3.502269^{*}$ \\
2007 & 0.001238 & 0.444126 & 2018 & -0.03629 & -0.04085 \\
2008 & -0.0059 & 0.592876 & & & \\
\hline
\end{tabular}

industrial advantages of the Northeast area can provide good technical support for the progress of green technology. The provinces belonging to the low-high agglomeration area are located in the northwest (1998) and the western area (2018). It can be seen that the AGTP in the southwest has less driving effect on the western area. It has yet to establish a completely competitive agricultural economic system and needs enough scientific and technical assistance, in particular, so the "low-high" agglomeration effect of AGTP is significant.

\section{Selection of spatial econometric model}

Before measuring and analyzing the model, we should judge the rationality of the model. The commonly used test methods are the Lagrange multiplier test (LM test), likelihood ratio test (LR test), and Wald test. From the test results in Table 4, it can be seen that the Lagrange test value (LM test value) and robust Lagrange test value (robust LM) of the spatial lag model and spatial error model under the economic weight matrix are positive at the significance level of $1 \%$, indicating that the spatial Doberman model (SDM) should be used. Meanwhile, the LR value and Wald test denied the original hypothesis is rejected at the significance level of $1 \%$, indicating that the SDM model should be the best choice compared with the SAR model and SEM model.

\section{Model selection of spatial spillover effects and analysis of results}

It can be seen from the above test that AGTP has significant spatial autocorrelation, so the current study uses a spatial measurement model to estimate the spatial spillover effects. Since the Hausman test values under the three spatial weight matrices are all significant at the $1 \%$ level, the null hypothesis that "random effects are better than fixed effects" is rejected. And the estimation result of the spatial fixed effect 
Fig. 4 The LASA cluster map of Chinese agriculture industry's AGTP in 1998 and 2018

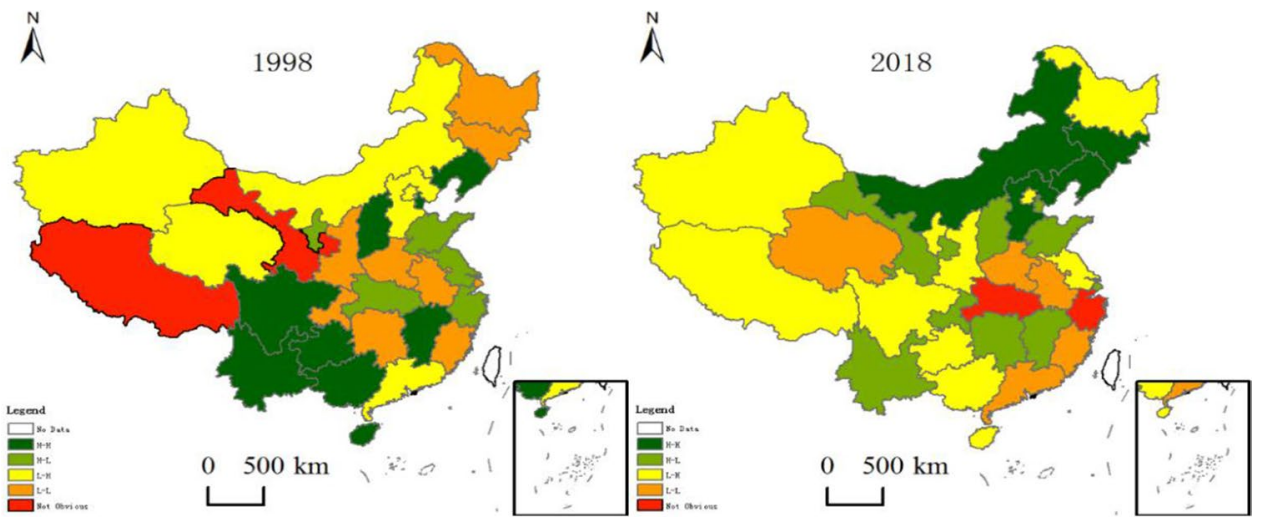

is the best under fixed time, fixed space, and dual fixed. Therefore, we use the spatial Doberman model based on fixed space to test and use the partial differentiation method of the SDM model to decompose the total effects under the three spatial weight matrices into direct effects and indirect effects. The results are shown in Table 5.

The results in Table 5 portray that the level of agricultural economic development has a positive impact on the progress of green technology in the area. GDP per capita, as part of the level of agricultural economic development, has also substantially aided the progress of green technology in the area. In terms of economic development, it is widely assumed that an area's economic growth may effectively support innovative activities, offer a material foundation for innovation, establish a suitable innovation environment, and increase information exchanges. This promotes the consolidation of technology, knowledge, and skills, as well as the enhancement of innovative consciousness and the development of innovation ambition (Yang et al. 2019). Therefore, we should focus on the research and promotion of green production technologies with market application value that has emerged as the primary driving force for agriculture to enhance profitability (Nelms et al. 2007). Simultaneously, Table 5 also reveals that the two indicators of the level of

Table 4 LM, LR, and Wald test results

\begin{tabular}{llr}
\hline Model & Index & \multicolumn{1}{l}{ Value } \\
\hline SAR & LM & $246.5315^{* * *}$ \\
& Robust LM & $107.2387 * * *$ \\
& LR & $149.8000^{* * *}$ \\
& Wald & $55.6360^{* * *}$ \\
SEM & LM & $275.6583 * * *$ \\
& Robust LM & $77.6370^{* * *}$ \\
& LR & $106.9900^{* * *}$ \\
& Wald & $59.6569 * * *$ \\
\hline
\end{tabular}

$* * *, * *$, and * represent the significance levels of $1 \%, 5 \%$, and $10 \%$, and the $Z$-value is in parentheses. agricultural economic development inhibited the spatial spillover effect of AGTP in the adjacent area, and the level of agricultural economic development in the adjacent area also has a negative impact on the spatial spillover effect of AGTP in the area, but both are not obvious. This demonstrates that the greater the level of agricultural economic development in the locality, the more evident it will be to encourage the progress of green technology in the area, but the influence on surrounding areas is non-significant. The reason is that with the development of the economy, organic fertilizers have replaced chemical fertilizers, green prevention, and control technologies such as biological control and physical control have gradually replaced pesticides, thereby promoting the progress of local green technologies. Nevertheless, the cropping industry's cross-regional market competitiveness is low, and its geographical radiation range is restricted. This might also explain why there is not a clear spatial spillover impact of green technological improvement between areas (Shen et al. 2021).

The level of labor has a negative impact on the progress of green technology in the area. All three types of weight matrix models pass the significance test, and their coefficients are all -0.0001 . The possible reason is that the labor factor has become relatively cheap, and the price distortion has destroyed the market principle of allocating labor resources to green technologically advanced farmers or agricultural enterprises. Simultaneously, conventional production techniques offer minimal risks, thus farmers or agricultural enterprises rely heavily on original production technology and equipment and extensively utilize unskilled and low-skilled labor for extended output. This is the path dependency of the extended development model of input of tangible components such as labor, which impedes green technological growth and has a low-end lock-in impact (Zou et al. 2018). Therefore, creating more adequate employment opportunities, providing a more stable employment environment, and a complete social security system will help provide an important guarantee for the green and highquality development of agriculture (Xu and $\mathrm{Wu}, 2020$ ). 
Table 5 The results of direct and indirect effects of the SDM model under spatial fixation

\begin{tabular}{|c|c|c|c|c|c|c|c|c|c|}
\hline \multirow[t]{2}{*}{ Variables } & \multicolumn{3}{|c|}{ Spatial adjacency weight matrix } & \multicolumn{3}{|c|}{ Geographic distance weight matrix } & \multicolumn{3}{|c|}{$\begin{array}{l}\text { Geographic economic distance weight } \\
\text { matrix }\end{array}$} \\
\hline & Direct effect & $\begin{array}{l}\text { Indirect } \\
\text { effect }\end{array}$ & $\begin{array}{l}\text { The total } \\
\text { effect }\end{array}$ & Direct effect & $\begin{array}{l}\text { Indirect } \\
\text { effect }\end{array}$ & $\begin{array}{l}\text { The total } \\
\text { effect }\end{array}$ & Direct effect & $\begin{array}{l}\text { Indirect } \\
\text { effect }\end{array}$ & $\begin{array}{l}\text { The total } \\
\text { effect }\end{array}$ \\
\hline Eco & $\begin{array}{l}0.0957^{* * * *} \\
(3.15)\end{array}$ & $\begin{array}{l}0.0197 \\
(0.43)\end{array}$ & $\begin{array}{l}0.1154^{* * *} \\
(2.76)\end{array}$ & $\begin{array}{l}0.1127^{* * *} \\
(3.93)\end{array}$ & $\begin{array}{l}-0.0194 \\
(-0.26)\end{array}$ & $\begin{array}{l}0.0933 \\
(1.35)\end{array}$ & $\begin{array}{l}0.1083^{* * *} \\
(3.68)\end{array}$ & $\begin{array}{l}-0.0187 \\
(-0.39)\end{array}$ & $\begin{array}{l}0.0896^{* *} \\
(2.43)\end{array}$ \\
\hline rjgdp & $\begin{array}{l}-0.0105^{*} \\
(-1.71)\end{array}$ & $\begin{array}{l}-0.0234^{*} \\
(-1.75)\end{array}$ & $\begin{array}{l}-0.0339^{* * *} \\
(-2.70)\end{array}$ & $\begin{array}{l}-0.0121^{* *} \\
(-2.57)\end{array}$ & $\begin{array}{l}-0.0209 \\
(-1.13)\end{array}$ & $\begin{array}{l}-0.0330^{*} \\
(-1.67)\end{array}$ & $\begin{array}{l}-0.0096 \\
(-1.55)\end{array}$ & $\begin{array}{l}-0.0271^{* *} \\
(-2.16)\end{array}$ & $\begin{array}{l}-0.0367^{* * *} \\
(-2.98)\end{array}$ \\
\hline Labor & $\begin{array}{l}-0.0001^{*} \\
(-1.92)\end{array}$ & $\begin{array}{l}-0.0001 \\
(-1.11)\end{array}$ & $\begin{array}{l}-0.0002^{*} \\
(-1.85)\end{array}$ & $\begin{array}{l}-0.0001^{* * *} \\
(-2.35)\end{array}$ & $\begin{array}{l}-0.0002 \\
(-0.87)\end{array}$ & $\begin{array}{l}-0.0003 \\
(-1.14)\end{array}$ & $\begin{array}{l}-0.0001^{* *} \\
(-2.50)\end{array}$ & $\begin{array}{l}-0.0002 \\
(-1.20)\end{array}$ & $\begin{array}{l}-0.0003^{*} \\
(-1.67)\end{array}$ \\
\hline City & $\begin{array}{l}0.0136 \\
(1.09)\end{array}$ & $\begin{array}{l}0.0002 \\
(0.01)\end{array}$ & $\begin{array}{l}0.0139 \\
(0.44)\end{array}$ & $\begin{array}{l}0.0264^{*} \\
(1.68)\end{array}$ & $\begin{array}{l}0.0016 \\
(0.03)\end{array}$ & $\begin{array}{l}0.0281 \\
(0.46)\end{array}$ & $\begin{array}{l}0.0033 \\
(0.33)\end{array}$ & $\begin{array}{l}0.0516 \\
(1.03)\end{array}$ & $\begin{array}{l}0.0548 \\
(1.18)\end{array}$ \\
\hline agst & $\begin{array}{l}-0.0373 \\
(-0.58)\end{array}$ & $\begin{array}{l}-0.2588^{* * *} \\
(-2.86)\end{array}$ & $\begin{array}{l}-0.2960^{* * * *} \\
(-2.87)\end{array}$ & $\begin{array}{l}-0.0024 \\
(-0.03)\end{array}$ & $\begin{array}{l}-0.2808 \\
(-1.52)\end{array}$ & $\begin{array}{l}-0.2832 \\
(-1.49)\end{array}$ & $\begin{array}{l}0.0068 \\
(0.10)\end{array}$ & $\begin{array}{l}-0.2905^{* * *} \\
(-2.88)\end{array}$ & $\begin{array}{l}-0.2837^{* *} \\
(-2.25)\end{array}$ \\
\hline ENVP & $\begin{array}{l}-0.0001 \\
(-0.88)\end{array}$ & $\begin{array}{l}-0.0003 \\
(-0.75)\end{array}$ & $\begin{array}{l}-0.0004 \\
(-0.85)\end{array}$ & $\begin{array}{l}-0.0001 \\
(-1.06)\end{array}$ & $\begin{array}{l}-0.0008 \\
(-1.50)\end{array}$ & $\begin{array}{l}-0.0009 \\
(-1.58)\end{array}$ & $\begin{array}{l}0.0000 \\
(-0.63)\end{array}$ & $\begin{array}{l}-0.0002 \\
(-1.18)\end{array}$ & $\begin{array}{l}-0.0003 \\
(-1.31)\end{array}$ \\
\hline ECOP & $\begin{array}{l}0.0036 \\
(0.47)\end{array}$ & $\begin{array}{l}-0.0282^{* *} \\
(-2.04)\end{array}$ & $\begin{array}{l}-0.0246 \\
(-1.48)\end{array}$ & $\begin{array}{l}0.0041 \\
(0.54)\end{array}$ & $\begin{array}{l}-0.0538^{* * *} \\
(-2.59)\end{array}$ & $\begin{array}{l}-0.0498^{\text {** }} \\
(-2.06)\end{array}$ & $\begin{array}{l}0.0025 \\
(0.36)\end{array}$ & $\begin{array}{l}-0.0324 \\
(-1.62)\end{array}$ & $\begin{array}{l}-0.0298 \\
(-1.35)\end{array}$ \\
\hline Rho & $\begin{array}{l}0.3794^{\text {**** }} \\
9.46\end{array}$ & & & $\begin{array}{l}0.3949^{* * *} \\
6.35\end{array}$ & & & $\begin{array}{l}0.2952^{* * *} \\
3.90\end{array}$ & & \\
\hline sigma $^{2} \mathrm{e}$ & $\begin{array}{l}0.0116^{\text {*** }} \\
3.74\end{array}$ & & & $\begin{array}{l}0.0118^{* * *} \\
3.88\end{array}$ & & & $\begin{array}{l}0.0123^{* * *} \\
3.89\end{array}$ & & \\
\hline $\begin{array}{l}\text { log-likeli- } \\
\text { hood }\end{array}$ & $\begin{array}{l}514.9778 \\
0.1911\end{array}$ & & & $\begin{array}{l}510.9499 \\
0.2047\end{array}$ & & & $\begin{array}{l}502.4969 \\
0.2004\end{array}$ & & \\
\hline$N$ & 651 & 651 & 651 & 651 & 651 & 651 & 651 & 651 & 651 \\
\hline
\end{tabular}

${ }^{* * *},{ }^{* *}$, and ${ }^{*}$ represent the significance levels of $1 \%, 5 \%$, and $10 \%$, and the $Z$-value is in parentheses.

Furthermore, there is no significant spatial spillover impact of labor level on AGTP in surrounding locations. The major reason for this is that rural excess labor is typically shifted to the urban areas in search of greater job possibilities (Knight et al. 2011). As a result, the influence on the progress of green technology in adjacent areas is non-significant.

The level of urbanization has a positive impact on the progress of green technology in the area, but only in the terms of geographic distance. The loss of labor force and economic development in the process of urbanization will bring crisis and opportunities to agriculture and will encourage the improvement of agricultural technology to some extent, although not significantly. The loss of rural human capital, on the other hand, limits the growth of agricultural mechanization and the development of the agricultural industrial chain. Simultaneously, due to land urbanization or the disposal of a large number of lands, non-agricultural employment demand growth is constrained. All these directly restrict the progress of green technology in the local area (Jiang et al. 2020). In particular, the construction of the ecological environment will be emphasized in the process of urbanization, which will further promote the spillover effect of green technology. Finally, the spatial spillover effect of the level of urbanization on the progress of green technology in neighboring areas is not significant. The possible reason is that economic development resources such as population and land in rural areas tend to be in the urban sector. There is not much influence on the economic and technological development of other rural places (Shang et al. 2018).

The direct effect of agricultural internal structure on the progress of green technology is -0.0373 , and the indirect effect is -0.2588 . This shows that for every $1 \%$ increase in the agriculture industry in the internal structure of agriculture, the probability of AGTP in local and foreign agriculture industries will decrease by 0.0373 and 0.2588 , respectively. The reason is that compared with other agricultural agriculture industries such as forestry and animal husbandry, agriculture production will increase the input of fertilizers, pesticides, machinery, and other carbon source products. With the popularization of agricultural mechanization and chemical products, ordinary farmers tend to be extensively managed, and there is little demand for green technologies that require a large amount of labor (Jiang et al. 2020). The agriculture industry is 
more suitable for large-scale agriculture to obtain higher economic profits. These intensified the extensive management mode of farmers and reduced the possibility of farmers' green technology. In addition, the agricultural internal structure in neighboring areas also has a significant negative impact on the progress of green technology in the area. The main reason is that foreign areas face the mode of obtaining market profits based on chemical and mechanization in the face of local technological progress and will conform to the market model (Zhou et al. 2021). As a result, a condition of "bad money pushing away good money" has emerged, reducing the likelihood of green technology adoption and AGTP by farmers outside the area.

The environmental policy of administrative (ENVP) has a negative impact on the progress of green technology in the local area and neighboring areas, and they are not significant. However, the "innovation-induced hypothesis" considers that environmental policies (such as emission fees/taxes and trading permits), as an external compulsory factor, make products more expensive explicitly or implicitly, thereby promoting technological innovation (Hicks 1963). The explanation might be that China's mandatory environmental laws are insufficient or ineffective in promoting the progress of agricultural green technologies. Thus, the government should through green environmental regulations and system design, implement a macro-layout for the green growth of area agriculture.

The environmental policy of economic (ECOP) has a positive impact on the progress of green technology in the area, but they are not significant. This is inconsistent with the result of the "innovation-induced hypothesis." The possible reason is that this study selected pollution control fees as an economic environmental policy. However, pollution control fees only control the pollution that has already occurred, which does not support the progress and innovation of green technology. On the contrary, due to the increased investment in pollution control costs, farmers or agricultural enterprises have "financial dependence." In other words, it is not important whether farmers or agricultural enterprises carry out technological innovation and green, because pollution will have funds, and it will even cause more pollution (Jiang and Li 2021). The government should provide greater policy assistance in the form of rules, funding, and platforms by defining the essential tasks of agricultural green development. This tends to increase the supply of agricultural green development policies, lowers the disguised and emphatic costs of agricultural green development, boosts the profitability of agricultural green development and boosts agricultural energy savings, emission reduction, and consumption reduction enthusiasm and initiative (Verweij et al. 2019).

\section{Conclusions and suggestions}

\section{Conclusions}

The dynamic monitoring of the advancement of green technology has garnered broad attention as the idea of green development has matured. The key to effectively establishing green development strategies and implementing environmental protection measures is to analyze its temporal and spatial dynamic evolution features and influencing factors. Taking the agriculture industry as an example, this study uses the EBM-GML model to measure the AGTP index and analyzes the temporal and spatial dynamic evolution characteristics of AGTP from 1998 to 2018 in 31 provinces in China. Finally, discussed its spatial spillover effects from three aspects: direct effects, indirect effects, and total effects. The main conclusions and inspirations are as follows:

(1) From the perspective of the temporal characteristics of AGTP, the development of AGTP in China's agriculture has a phased characteristic of "rising first and then falling," and there is obvious regional unevenness in development. At the same time, the kurtosis decreased year by year, the width expanded year by year, and the number of peaks gradually changed from a single peak to a double peak. The degree of regional concentration of AGTP has declined, and regional differences have widened.

(2) From the perspective of the spatial distribution characteristics of AGTP, the spatial autocorrelation test results of AGTP at the global level are significantly positively correlated. While the regional level of interprovincial AGTP in agriculture shows agglomeration characteristics in space. Among them, the provinces in the "high-high" agglomeration area are located in the southwest (1998) and northeast (2018). The provinces in the "low-high" agglomeration area are located in the northwest (1998) and western area (2018). In particular, the progress of green technology in the southwest has little effect on the surrounding areas.

(3) From the perspective of the spatial spillover effects of AGTP, the difference in spatial spillover effects of AGTP under different spatial weights is relatively small. The level of agricultural economic development, GDP per capita and the level of urbanization have significantly promoted the progress of agricultural green technology in the local and adjacent areas. Agricultural internal structure and the level of labor have inhibited the progress of green agricultural technology in the local and neighboring areas. In addition, both the environmental policies of administrative (ENVP) and eco- 
nomic environmental policies (ECOP) have a negative impact on the progress of green technology in neighboring areas. The imperative environmental policies (ENVP) and economic environmental policies (ECOP) have negative spillover effects and positive spillover effects on the progress of agricultural green technology in the area, respectively.

\section{Policy suggestions}

The above conclusions are of great significance at the policy level. Firstly, according to the previous conclusions, different regions have different levels of green technology, so we should improve the level of agricultural economic development, per capita GDP, and urbanization. At the labor level, we must use the corresponding technology to adjust the capital and labor input in the production process, realize the optimal allocation of rural labor resources and optimize the relationship between man and land. At the same time, the government should improve the positive role of economic and environmental policy (ECOP), avoid the obstructive effect of mandatory environmental policy (ENVP), improve the policy implementation system, and mobilize the public to participate in environmental governance. Secondly, regional heterogeneity of green technological progress indicates that policy should tend to low-low concentration areas and narrow the labor productivity gap between them and high-high concentration areas. At the same time, we can try to establish a bilateral or multilateral regular exchange system and further strengthen technical exchange and diffusion as well as institutional arrangements. The AGTP developed areas should play the role of model pacesetter and actively promote the technological progress of surrounding areas through technology diffusion. At the same time, the AGTP underdeveloped areas need to improve their own technology promotion system and create a favorable promotion environment to avoid the further widening of the inter-provincial gap caused by blocked technology promotion. Finally, the government should actively develop a compensation mechanism for ecological environment damage, an effective resource management system, and a later tracking and oversight mechanism during the policy design and implementation process.

In addition, agricultural economic activities in the background of novel coronavirus will also have a significant impact. The new coronavirus urgently needs to restore the livelihood activities of affected farmers, which requires the role of technology. Adhere to the concept of agricultural green progress, improve farmers' green production technology, and reduce pollution. Respecting nature, loving nature, conforming to nature, and coexisting in harmony with all things in nature is an important part of preventing the invasion of viruses, and it is the long-term survival of mankind.
Supplementary Information The online version contains supplementary material available at https://doi.org/10.1007/s11356-021-18424-z.

Author contribution Yue Deng: conceptualization, methodology, writing — original draft, software, writing — review and editing, and visualization. Sufyan Ullah Khan: investigation, editing, formal analysis, and writing-review and editing. Yu Cui: data curation, methodology, and formal analysis. Minjuan Zhao: supervision and funding acquisition. Qian Lu: data curation, investigation, and supervision.

Funding The authors gratefully acknowledge the financial support from the National Natural Science Foundation of China (NSFC) under grant no. 15ZDA052, the National Natural Science Foundation of China (grant no. 71973105), the Key Special Funds of the Ministry of Agriculture and Ministry of Finance (grant no. CARS-07-F-1), Key Project of Six Industrial Research Institutes of Northwest Agricultural and Forestry University (grant no. Z221021601), and Scientific Research and Innovation Projects of Northwest A\&F University (no. JGYJSCXXM202001). We truly appreciate all the peer reviewers for their valuable suggestions, meanwhile, we would like to thank all the co-authors and anonymous referees for their help and corrections on the earlier draft of our paper, according to which we improved the content.

Data availability The datasets used and/or analyzed during the current study are available from the corresponding author on reasonable request.

\section{Declarations}

Ethics approval This is an observational study. We confirmed that no ethical approval is required.

Consent to participate Not applicable.

Consent to publish Not applicable.

Competing interest The authors declare no competing interests.

\section{References}

Acemoglu D (2000) Labor- and capital- augmenting technical change. NBER Working Papers 1:1-37

Acemoglu D (2007): Equilibrium bias of technology, National Bureau of Economic Research, Inc, pp. 1371-1409

Acemoglu D, Aghion P, Bursztyn L, Hemous D (2011): The environment and directed technical change. CEPR Discussion Papers, $1-64$

Acemoglu D, Aghion P, Bursztyn L, Hemous D (2012) The environment and directed technical change. American Economic Review 102:131-166

Doranova A, Costa I, Duysters G (2010) Knowledge base determinants of technology sourcing in clean development mechanism projects. Energy Policy 38:5550-5559

Elhorst, Paul J (2014): Matlab software for spatial panels. International Regional Science Review, 1-23

Emilio P, Mercedes S, Verstegen J, Thomas L (2018) Searching for the entrepreneurs among new entrants in European agriculture: the role of human and social capital. Land Use Policy 77:19-30

Feng G, Serletis A (2014) Undesirable outputs and a primal Divisia productivity index based on the directional output distance function. J Econometrics 183:135-146 
Fischer C, Heutel G (2013): Environmental macroeconomics: environmental policy, business cycles, and directed technical change. UNCG Economics Working Papers, 197-210

Gerber MS (2014) Predicting crime using Twitter and kernel density estimation. Decis Support Syst 61:115-125

Guo H, Xu S, Pan C (2020) Measurement of the spatial complexity and its influencing factors of agricultural green development in China. Sustainability 12:1-18

He W, Li E, Cui Z (2021) Evaluation and influence factor of green efficiency of China's Agricultural innovation from the perspective of technical transformation. Chin Geogra Sci 31:313-328

Hicks JR (1963): The theory of wages. Palgrave Macmillan UK

Horbach J, Rammer C, Rennings K (2012) Determinants of ecoinnovations by type of environmental impact - the role of regulatory push/pull, technology push and market pull. Ecol Econ $78: 112-122$

$\mathrm{Ji}, \mathrm{Li}$ (2019) Research on green technological progress measurement and influencing factors in marine aquaculture industry in China. J Ocean Univ China(Social Sci) 2 51-56

Ji Y, Wang Y (2014) Some comments on Antonelli and Quatraro's paper of measuring effect of biased technology on TFP. J Technol Transfer 39:276-280

Jiang M, Hu X, Chunga J, Lin Z, Fei R (2020) Does the popularization of agricultural mechanization improve energy-environment performance in China's agricultural sector? J Clean Prod 276:124210

Jiang SS, Li JM (2021) Do political promotion incentive and fiscal incentive of local governments matter for the marine environmental pollution? Evidence from China's coastal areas. Marine Policy 128:104505

Knight J, Deng Q, Shi L (2011) The puzzle of migrant labour shortage and rural labour surplus in China. China Econ Rev 22:585-600

Kou M, Chen K, Wang S, Shao Y (2016) Measuring efficiencies of multi-period and multi-division systems associated with DEA: an application to OECD countries' national innovation systems. Expert Syst Appl 46:494-510

Lesage J, Pace RK (2008): Introduction to spatial econometrics. rei, $19-44$

Levain A, Vertes F, Ruiz L, Delaby L, Gascuel-Odoux C, Barbier M (2015) 'I am an intensive guy': the possibility and conditions of reconciliation through the ecological intensification framework. Environ Manage 56:1-15

Li G (2014): The green productivity revolution of agriculture in China from 1978 to 2008. China Economic Quarterly, 117-138

Li J ZC (2020): Research on green output bias of China's agricultural technology progress and its influence factors: bias decomposition of technology progress output based on agricultural green TFP growth during 1999 -2018. West Forum, 1674-8131

Li. J, Z. C (2020): Research on green output bias of China's agricultural technology progress and its influence factors: bias decomposition of technology progress output based on agricultural green TFP growth during 1999 -2018. West Forum 1674-1813

Liu Y, Zhu J, Li EY, Meng Z, Song Y (2020) Environmental regulation green technological innovation and eco-efficiency: the case of Yangtze river economic belt in China. Technol Forecast Soc Change 155:119993

Lovely M, Popp D (2011) Trade, technology, and the environment: does access to technology promote environmental regulation? J Environ Econ Manag 61:16-35

Morya CP, Punia M Impact of urbanization processes on availability of ecosystem services in National Capital Region of Delhi (19922010). Environment Development and Sustainability

Nelms CE, Russell AD, Lence BJ (2007) Assessing the performance of sustainable technologies: a framework and its application. Build Res Inform 35:237-251

Nyam YS, Kotir JH, Jordaan AJ, Ogundeji AA (2021) Developing a conceptual model for sustainable water resource management and agricultural development: the case of the Breede River catchment area, South Africa. Environ Manage 67:632-647

Oh DH (2010) A global Malmquist-Luenberger productivity index. J Prod Anal 34:183-197

Onanuga MY, Eludoyin AO, Ofoezie IE (2021): Urbanization and its effects on land and water resources in Ijebuland, southwestern Nigeria. Environment, Development and Sustainability, 1-25

Pan X, Liu Q, Peng X (2015) Spatial club convergence of regional energy efficiency in China. Ecol Ind 51:25-30

Popp D (2004) ENTICE: endogenous technological change in the DICE model of global warming. J Environ Econ Manag 48:742-768

Qin B, Xiao F (2018a): A non-parametric method to determine basic probability assignment based on kernel density estimation. IEEE Access, 73509 - 73519

Qin B, Xiao F (2018b): A non-parametric method to determine basic probability assignment based on kernel density estimation. IEEE Access, 1-1

Razmi A (2013) Environmental macroeconomics simple: stylized frameworks for short-run analysis. Umass Amherst Econ Work Papers 44:212-217

Ren W, Zeng Q (2021) Is the green technological progress bias of mariculture suitable for its factor endowment? _-empirical results from 10 coastal provinces and cities in China. Marine Policy 124:104338

Shang J, Wang Z, Li L, Chen Y, Li P (2018): A study on the correlation between technology innovation and the new-type urbanization in Shaanxi province. Technol Forecast Soc Change, 266-273

Shen Y, Cui B, Wang Y, Cui H (2021): Marketing strategy and environmental safety of nano-biopesticides - scienceDirect. Advance Nano-Fertilizers and Nano-Pesticides in Agriculture, 265-279

Shuqin M, Dai J, Wen H (2019) Trade openness, environmental regulation and green technology progress_— spatial econometric analysis based on provincial data in China. J Int Trade 10:132-145

Song M, Wang S, Wu K (2016) Environment-biased technological progress and industrial land-use efficiency in China's new normal. Ann Oper Res 268:425-440

Tone K (2001) A slacks-based measure of efficiency in data envelopment analysis. Eur J Oper Res 130:498-509

Verweij P, Cormont A, Hoetjes P, Meyer KD, Janssen S (2019) Codesigning a data platform to impact nature policy and management: experiences from the Dutch Caribbean. Environ Sci Policy 100:13-20

Vocke G, Heady EO (1978) Impact of pesticide restrictions on regional production patterns. Water Air Soil Pollut 10:105-114

Wang H, Wang L, Yang G, Jia L, Zhang Y (2018) Agricultural water resource in China and strategic measures for its efficient utilization. Chinese Journal of Engineering Science 20:9

Wang Y, Tao Z, Wang J, Guo F, Xu K, Rong Y (2018b): Spatial analysis on carbon emission abatement capacity at provincial level in China from 1997 to 2014: an empirical study based on SDM model. Atmos Pollution Res, 97-104

Wanzenboeck I, Scherngell T, Brenner T (2016) Agroecology and permaculture: addressing key ecological problems by rethinking and redesigning agricultural systems. J Environ Stud Sci 6:239-250

Xu HSN, Wu LL (2020) High-quality development level and its spatiotemporal changes in the Yellow River Basin. Res Sci 42:115-126

Xu S (2021): Do foreign direct investment and environmental regulation improve green technology innovation? An empirical analysis based on panel data from the Chinese manufacturing industry. Environmental Science and Pollution Research, 1-13

Yang G, Zha D, Zhang C, Chen Q (2020a) Does environment-biased technological progress reduce $\mathrm{CO} 2$ emissions in APEC economies? Evidence from fossil and clean energy consumption. Environ Sci Pollut Res 27:20984-20999 
Yang J, Cai W, Ma M, Li L, Chen X (2019) Driving forces of China's $\mathrm{CO} 2$ emissions from energy consumption based on Kaya-LMDI methods. Sci Total Environ 711:134569

Yang Z, Shao S, Fan M, Yang L (2020b): Wage distortion and green technological progress: a directed technological progress perspective. Ecol Econ 106912

Zhang J, Lu G, Skitmore M, Ballesteros-Pérez P (2021) A critical review of the current research mainstreams and the influencing factors of green total factor productivity. Environ Sci Pollut Res 28:35392-35405

Zhang S, Zhao X, Yuan C, Wang X (2020) Technological bias and its influencing factors in sustainable development of China's transportation. Sustainability 12:1-26
Zhang Y, Wang J, Xue Y, Yang J (2018) Impact of environmental regulations on green technological innovative behavior: an empirical study in China. J Clean Prod 188:763-773

Zhou X, Cai Z, Tan KH, Zhang L, Song M (2021) Technological innovation and structural change for economic development in China as an emerging market. Technol Forecast Soc Change 167:120671

Zou X, Ye X, Yin G (2018) Labor quality and production technology in provincial China. Soc Sci J 56:588-598

Publisher's note Springer Nature remains neutral with regard to jurisdictional claims in published maps and institutional affiliations. 